\title{
Low Cost Arduino Based Smart Parking Lot Controller with Occupancy Counter
}

\author{
Mallikarjun.G.Hudedmani'*, B.H.Harikishan², N.Sharath ${ }^{3}$, M.Rakesh ${ }^{4}$ \\ Department of Electrical and Electronics Engineering, KLE Institute of Technology, Opposite to Airport,
} Gokul, Hubballi , Karnataka, India

\begin{abstract}
The present world is witnessing tremendous growth in technology and practices. In the global perspective, day to day the number of four wheelers i.e, cars is increasing. The safety and parking the four wheelers has become a major concern and need attention in this regard. Safe, secure and automatic parking is need of the hour. An electronic circuitry and Arduino UNO controller is used to design and detect the car when it approaches to the gate of parking space and provides the parking space for it if free slots are available. The smart parking also display the number of occupied vehicles count on the display provided max of 9 in the present work and can be extended. Such a smart parking lot doesn't require a security officer to monitor. This provides cheap and easy solutions to parking problems.
\end{abstract}

KEYWORDS: Smart Parking, Arduino based Parking Controller, Automatic Parking

\section{INTRODUCTION}

The present life style and living comforts are giving rise to a heavy traffic of vehicles inside the city. The associated problem with this is to handle and accommodate the vehicles in parking system is very challenging [1]. The conventional parking systems are not having sufficient area and any such display units to display vehicles count after having entered into or on the vacation of a vehicle. There are many such solutions to the parking problem with the use of microcontroller and associated safety and controls. Similarly few of the parking system have proposed camera and image processing, GSM and internet of things (IoT) based approach to intimate and exchange information for the request of parking space [2-3]. Some of the presentations in this regard are simulated in software packages to understand the feasibility and opportunity to implement [4]. The current advances in wireless communication technology lead to the use of IoT (Internet of Things) based parking lot management and remotely enquiring the availability of the space to park the vehicle [5]. The application of computer vision to identify the empty space in the parking area is also found in few publications and accordingly allocation of space takes place for the incoming vehicle [6]. A IoT based parking system proposal and model for airport taxi area was presented and its features were noted [7]. Literature has provided the cases of study and application of RFID (Radio frequency identification tag) to allot and locate the vehicle in the parking lot to minimize time and ensure safety [8]. The inter based booking of parking space for the vehicle in advance like travel ticket booking was found and that concept used cloud based data management [9]. A specific computer algorithm based image processing using OCR (Optical character reading) found used to identify the specific vehicles of group of reserved peoples or employees. This also helps in managing some special allocation schemes for men and women and differently able peoples etc [10].

The current work on automatic parking lot with a vehicle occupancy counter uses Arduino controller to overcome the problem of vehicle count or availability of space to park. The circuit automatically detect the presence of car in front of the gate and do not use any complex circuitry. Then it verifies whether the space in the parking lot is available or not. For a case if there exists an empty space to house the incoming car then it opens the gate of the parking lot otherwise it does not. The revised count of parking slots availability for parking is displayed on the common anode display.

\section{BLOCK DIAGRAM AND WORKING}

The complete inter connection of the components is shown in Fig1. This circuit uses an Arduino UNO which is programmed in such way that it displays the count of existing cars inside the parking lot and detects the car when it approaches the parking lot. The presence of car in front of gate is sensed by a pair of sensors in the papers which serves as the parking lot. There are three sheets of heavy stock; the top and bottom both have aluminium foil on them, with the centre layer as a separator. There are holes cut in the separator where the hash marks can be seen above. By the small pressure created by the car when driven on this sensing sheet completes the circuit instructing the Arduino about the presence of a vehicle in the proper position. Next the Arduino checks whether the parking lot is empty or not.

The vehicle can be driven in and after this the display counter is incremented and displayed. To exit the parking lot the circuit performs similar functioning in which the count is suitably modified and displayed. The working of the proposed model is shown in Fig 2 through Fig 5 sequentially step by step.

\section{*Corresponding Author: mallikarjunh@yahoo.com}

Received: 11.12.2018 Accepted: 18.01.2019 Published on: 27.02.2019 
Fig 1 shows a situation where parking lot is completely empty and the Fig 2 shows the basic empty startup outlook of the arrangement. Fig 3 shows a car requesting for parking and the display of vacant count 9 is observed with gate closed.

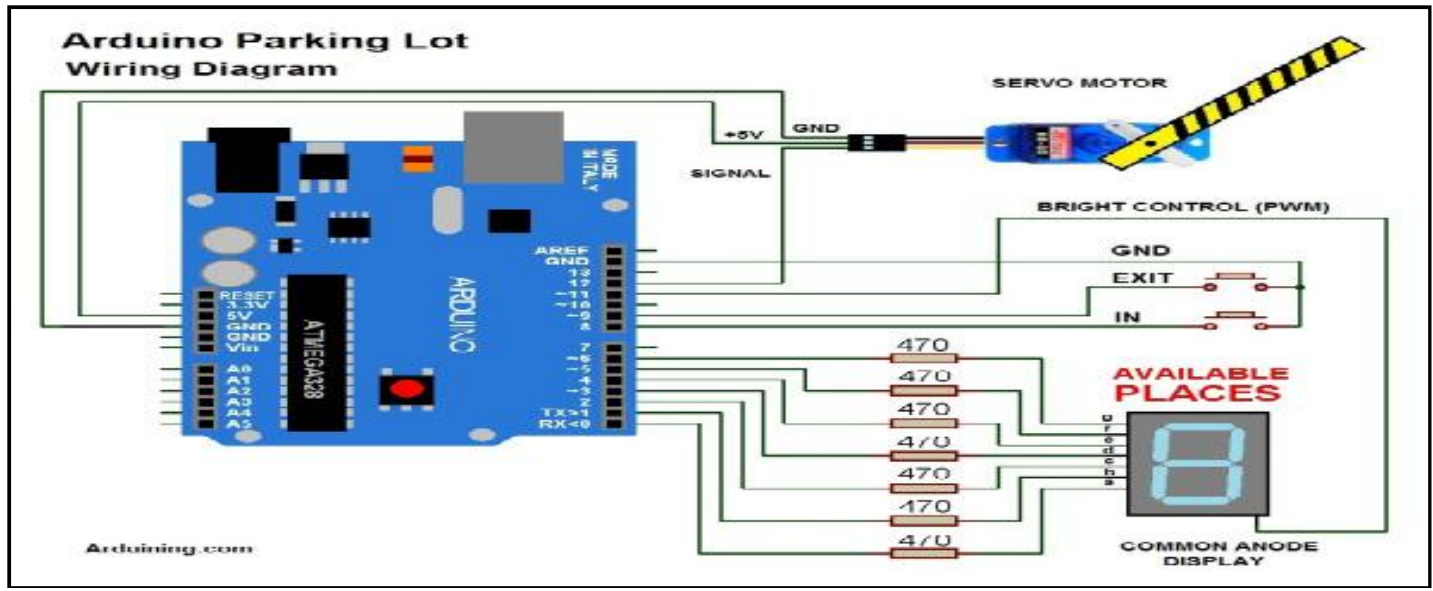

Figure 1 Block diagram of Smart Parking lot Arduino

(Courtesy: https://arduining.com )

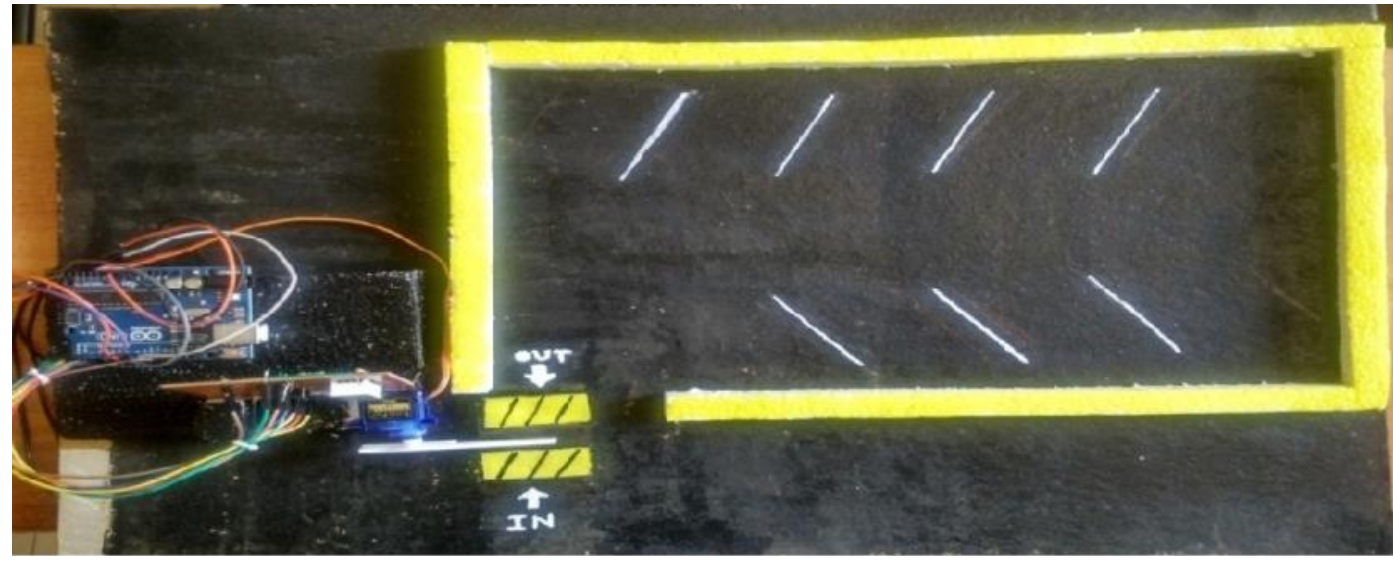

Figure 2 Experimental setup for the Smart Parking lot with Arduino

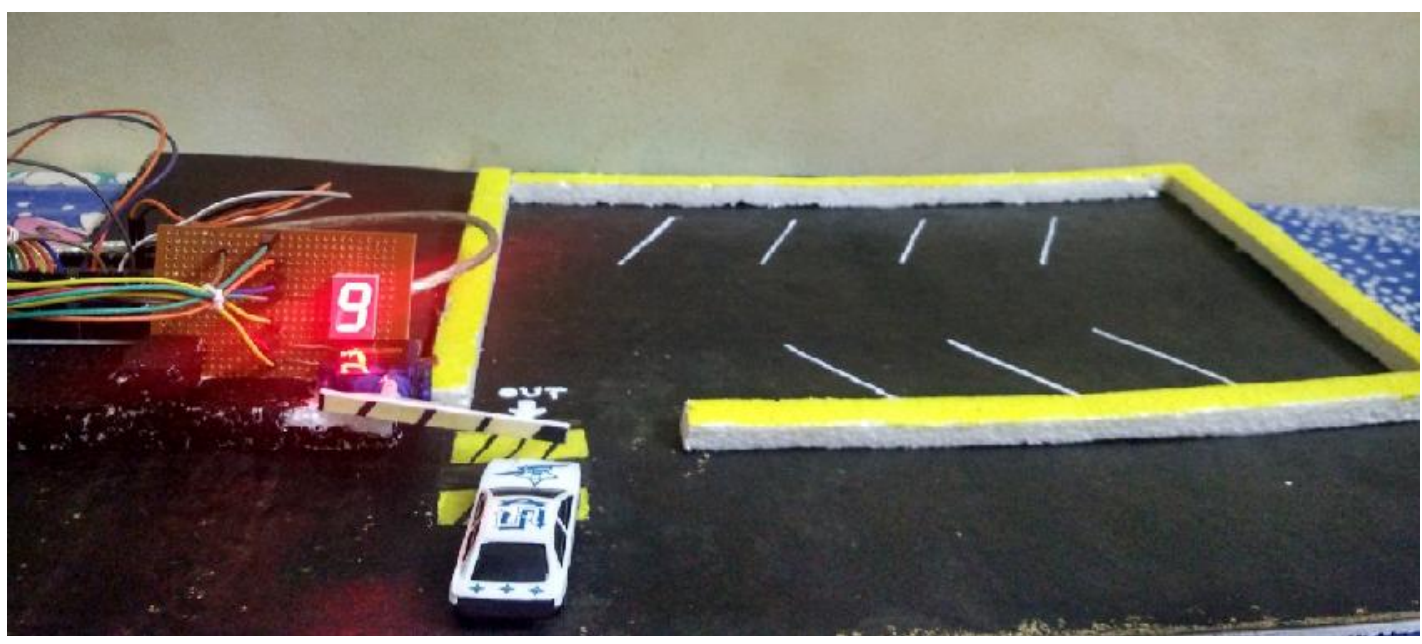

Mallikarjun.G.Hudedmani et al., 
Figure 3 Experimental setup for the Smart Parking lot with Arduino and waiting car

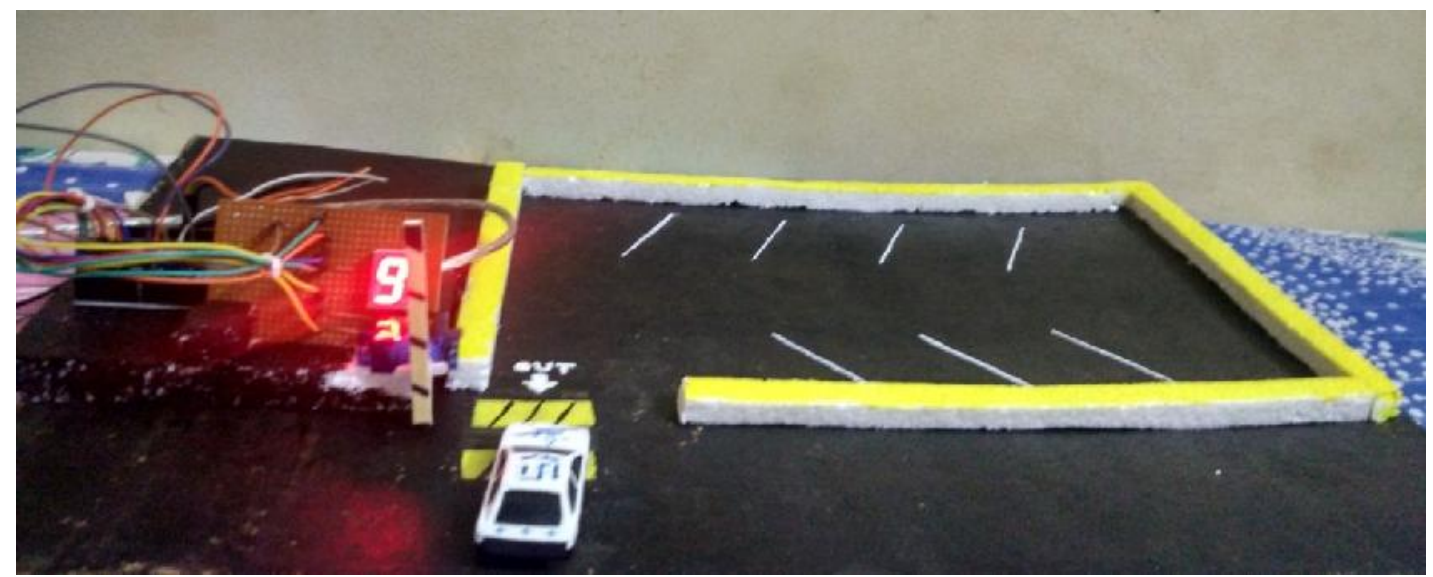

Figure 4 Experimental setup for the Smart Parking lot Arduino with Bar up

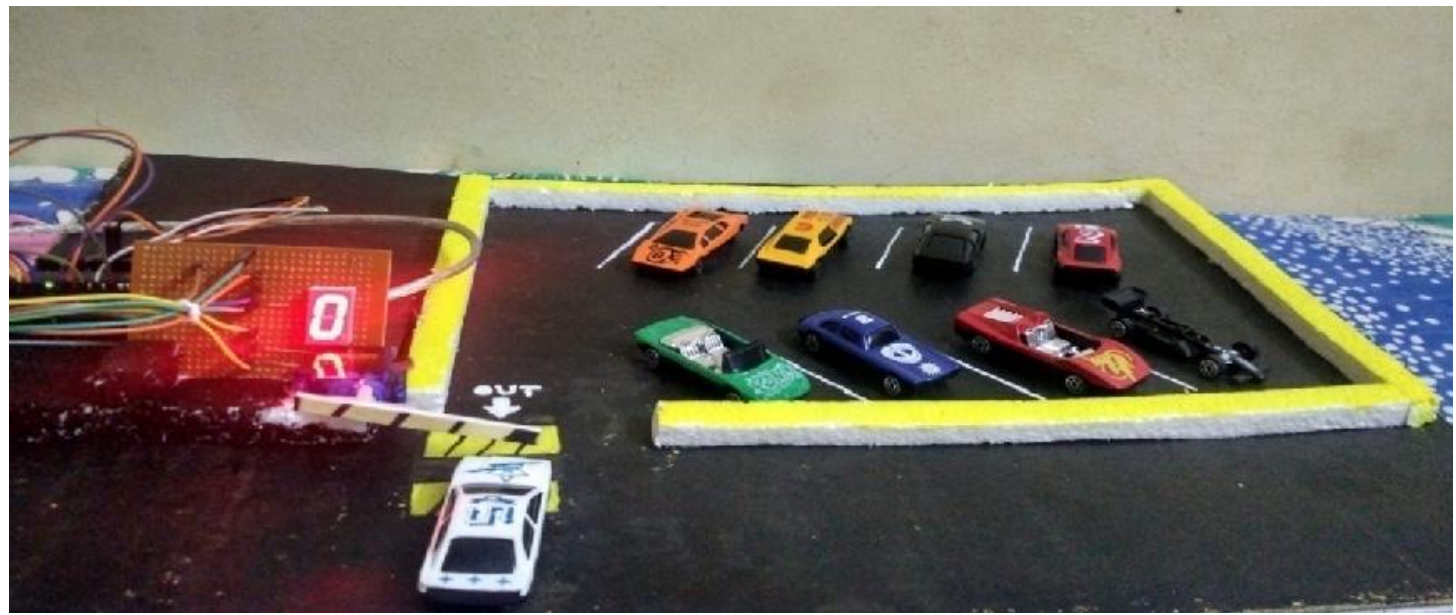

Figure 5 Experimental setup for the Smart Parking lot Arduino with Parking Full status

Table 1: Step by step procedure used to create the code

\begin{tabular}{|c|l|}
\hline STEP & \multicolumn{1}{c|}{ DESCRIPTION } \\
\hline 1 & Set the Arduino programming environment with suitable library headers \\
\hline 2 & Define and configure the input and out pins for the task \\
\hline 3 & Calibrate the servo motor bias count for the proper position of the Bar \\
\hline 4 & Configure and connect the seven segment display unit to the Arduino pins \\
\hline 5 & Keep checking the request for the parking from sensor input at the door entry/exit \\
\hline 6 & Open the Bar for the parking of a vehicle and modify the counts on the display \\
\hline 7 & Repeat the step if any vehicle go out by updating the count suitably \\
\hline 8 & Keep the loop active for the entry or exit of vehicles continuously \\
\hline
\end{tabular}

When the car gets the permission to park then gate is completely opened as shown in Fig 3 and Fig 4. It continues similarly for all the slots. The completely housed lot is observed Fig 5 with available parking slot count zero. The count will change if any of the cars exit from the parking lot giving an opportunity to park.

The proposed concept is very useful in Shopping malls, Educational institutes, Government organization etc. This helps in optimized parking. Users find the best spot available, saving time, resources and effort. The parking lot fills up efficiently and space can be utilized properly by commercial and corporate entities. This system not only provides increased safety it decreases management Costs. This system use power supply continuously as required for the working of this system. The system requires regular maintenance and checking. The Table 1 shown below presents the step by step sequences followed in developing the code for the proposed concept.

\section{Mallikarjun.G.Hudedmani et al.,}




\section{DESCRIPTION OF THE COMPONENTS USED}

Experimental set up of the work proposed was carried out on the work bench by making use of following components.

\subsection{Arduino UNO and Servo motor}

The Arduino is a low power consuming, low cost open source supported microcontroller for the creative developers and engineers. The controller board support digital and analog data input and outputs. Communicate with peer devices for exchange of information and data for the control. The GNU General Public License (GPL) permits the manufacture of Arduino boards and software distribution by anyone. Fig 6 presents the pictorial view of the controller.

The servomotor as shown in Fig 7 is an actuator used in much of the robotic applications for the action and position control. The servomotor is having its own feedback circuit hence very much suitable for closed-loop control system and CNC machinery or automated manufacturing.

\subsection{Resistors and Common anode LED display}

To rig up an electronic circuit several components are required like, resistors, capacitor and display units etc. The carbon resistors used are of $1 / 4^{\text {th }}$ watt as shown in Fig 8. They are used to control and limit the current in the electronic circuit to function for the intended activity and situation. Seven segment display units are low cost and moderate power consuming display devices used in various circuits to indicate the information visually. A single seven segment display unit as shown in Fig 9 can show a highest number 9. A common anode unit need a low signal on each segment to light the segment but a common cathode need a positive signal.

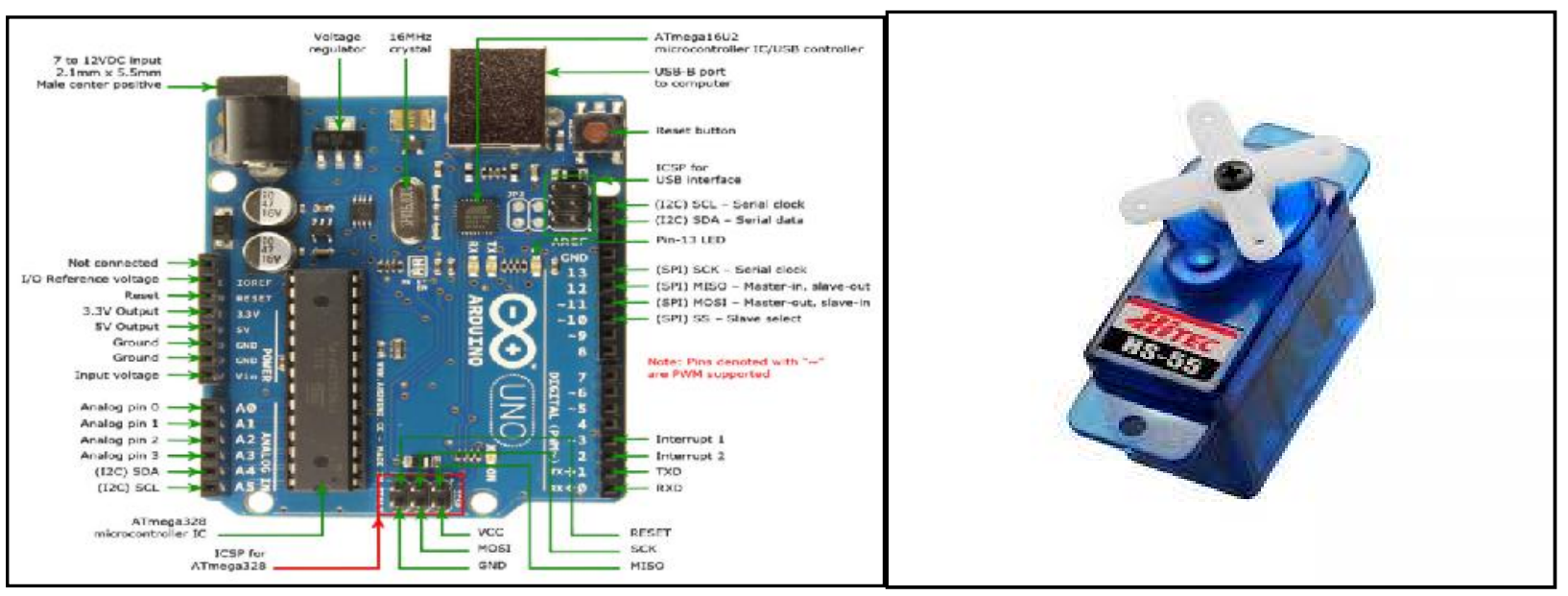

Figure 6 Arduino pin out

Figure 7 DC Servo motor (Courtesy : https://ROBOMART.com)

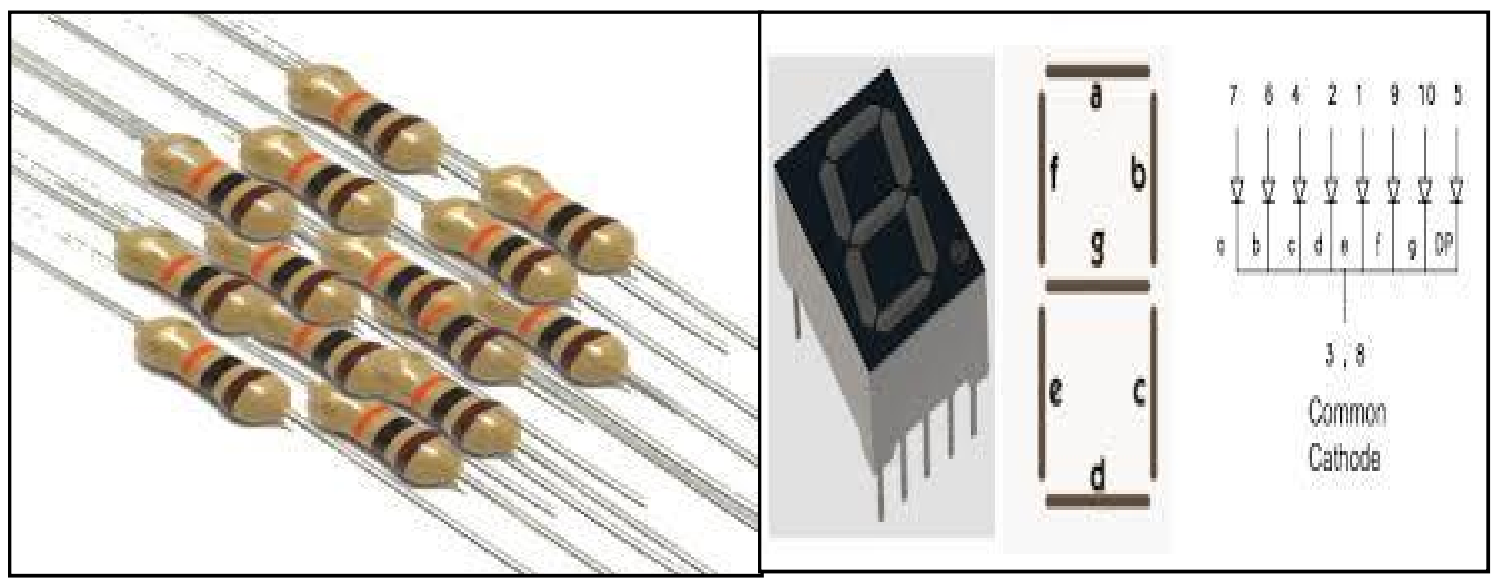

Figure 8 Carbon resistor

Figure 9 Seven segment LED 


\section{CONCLUSION}

Smart parking lot with counter is an electro-mechanic setup which detects and provides parking space. The smart parking lot with counter presented is a part of a complete security and automated parking system. It is efficient and reliable. This system doesn't require human aid except while maintenance. It provides solution to parking problems. As a scope for improvement for this circuit, the allotment of specific parking space number is used per car. Then random parking can be avoided. Interfacing with IoT peripherals to send and receive the information from remote place and accident prevention circuits adds values to this work. The specific enquiry regarding availability of parking slot and booking can be worked out. A parking lot with IoT and time based system is the upcoming extension of the work.

\section{REFERENCES}

[1]. Towhid Chowdhury,MD., Ebad Zahir, Automotive Parking Lot and Theft Detection through Image Processing, 2013, American Journal of Engineering Research, 02-10, page 308-313.

[2]. Herdis Herdiansyah, Sugiyanto, Andrew Guntur Octavianto, Edison,Guntur Aritonang, Malya Nova Imaduddin, Dedi, Magfira Rilaningrum, 2017, Capacity Analysis Of Parking Lot And Volume of Vehicle Toward Sustainable Parking Convenience, IOP Conference Series: Earth and Environmental Science, 88, 1, 012031.

[3]. Hina Kousar, Kavitha Kumar, Shoney Sebastian, 2015, Reservation Based Parking System with Dynamic Slot Allocation, International Journal of Scientific and Research Publications, 5-3.

[4]. Fabros,JP., D Tabañag,A Espra, OJ Gerasta, 2015, Automated Car Park Management System, IOP Publishing IOP Conf. Series: Materials Science and Engineering, 79, 1-7.
[5]. Abhirup Khanna, Rishi Anand, IoT based Smart Parking System, 2016, International Conference on Internet of Things and Applications (IOTA) Maharashtra Institute of Technology, Pune.

[6]. Hilal Al-Kharusi, Ibrahim Al-Bahadly, 2014, Intelligent Parking Management SystemBased on Image Processing, World Journal of Engineering and Technology, page 55-67.

[7]. Suresh,M., P.Saravana Kumar, T.V.P.Sundararajan, 2015, IoT Based Airport Parking System, IEEE Sponsored 2nd International Conference on Innovations in Information, page 1-5.

[8]. Hemant Chaudhary, Prateek Bansal, Dr. B.Valarmathi, 2017, Advanced CAR Parking System using Arduino, International Conference on Advanced Computing and Communication Systems (ICACCS -2017).

[9]. Karthi.M, Preethi Harris, 2016, Smart Parking With Reservation In Cloud Based Environment, IEEE International Conference on Cloud Computing in Emerging Markets (CCEM), 9-12.

[10]. Sagar Rane, Aman Dubey, Tejisman Parida, 2017, Design of IoT Based Intelligent Parking SystemUsing Image Processing Algorithms, Proceedings of the IEEE International Conference on Computing Methodologies and Communication(ICCMC),

All (c) 2019 are reserved by International Journal of Advanced Science and Engineering. This Journal is licensed under a Creative Commons Attribution-Non Commercial-ShareAlike 3.0 Unported License.

Mallikarjun.G.Hudedmani et al., 